\title{
Surge Characteristics of Propulsion Coils Including Mutual Coupling for Maglev
}

\author{
Masato ANDO \\ Yoshinobu NAKAMICHI, Dr. Eng. \\ Chief Researcher \\ Kohji AJIKI \\ Researcher, \\ Power supply systems G., Power supply technology Div. \\ Hidenori SHIGEEDA \\ Assistant Manager, Yamanashi Maglev Test Center \\ Masao SUZUKI \\ Senior Researcher, Guideway Engineering G., \\ Research \& Development Div., Maglev System Development Dept. \\ The Maglev system employs a linear synchronous motor (LSM) with the primary side on \\ the ground, and uses a combined levitation-guidance system and double-layered propulsion \\ coils. To analyze electric surge propagation, we measured the surge propagation between \\ propulsion coils. We also set up simulation models and simulated the surge propagation by \\ using the Electro-Magnetic Transients Program (EMTP). It was found that the measured \\ values agreed well with the values simulated by EMTP. Therefore, it was verified that the \\ proposed surge propagation models for simulation were very useful to estimate the surge \\ propagation of coils used for Maglev.
}

Assistant Senior Researcher,

Keywords : Maglev, propulsion coil, levitation-guidance coil, surge, EMTP

\section{Introduction}

A superconducting magnetic levitation system (Maglev) has been developed since 1977 in Japan. The system employs a linear synchronous motor (LSM) with the primary side on the ground, and uses a combined levitation-guidance system with double-layered propulsion coils arranged on the surface of the sidewall. Doublelayered propulsion coils reduce the magnetic fluctuating force for the superconducting coils. Propulsion coils are electro-magnetically coupled with each other to compose double-layered attachment. In addition, the propulsion coils on both sidewalls are electro-magnetically coupled with the combined levitation-guidance system. Therefore, the system is very complicated from the viewpoint of surge propagation analysis. To analyze the electric surge propagation of such an electro-magnetically complicated Maglev system, we measured the surge propagation between propulsion coils by using an impulse generator. We also set up simulation models in consideration of mutual coupling between coils and simulated the surge propagation by using the Electro-Magnetic Transients Program (EMTP). It was found that the measured values agreed well with the values simulated by EMTP. Therefore, the surge propagation models proposed in this paper appeared to be useful for the numerical estimation of the surge propagation of coils.

\section{Coil attachment in the Yamanashi Maglev test line}

The Yamanashi Maglev test line uses double-layered propulsion coils and sidewall levitation-guidance coils system. Figure 1 shows an example of coil attachment ${ }^{1)}$.

The propulsion coils are oval in shape, and double-

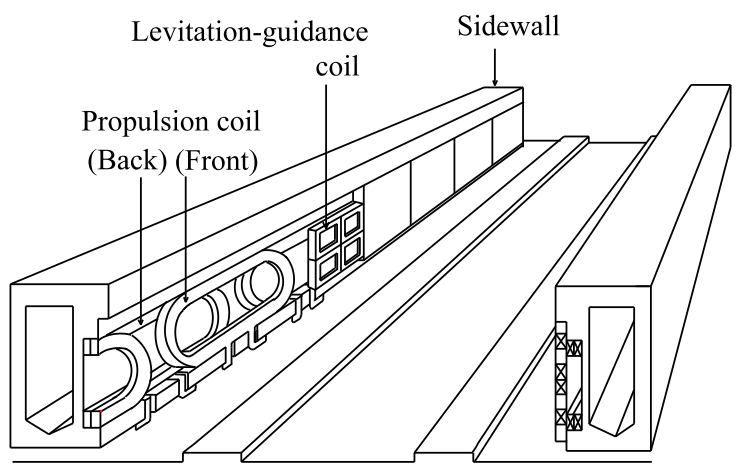

Fig. 1 Example of coil attachment

layered to reduce the magnetic fluctuating force for the on-board superconducting coils ${ }^{2}$. The sidewall levitationguidance coils are 8-shaped, and two coils each on both sidewalls are connected with a null flux cable to guide the vehicle along the guide way. This makes the propulsion coils on both sidewalls electro-magnetically coupled with the combined levitation-guidance system.

\section{Surge propagation characteristics between coils}

Before the construction of the Yamanashi Maglev test line, the double-layered propulsion coil and sidewall levitation-guidance coil system were installed on part of the Miyazaki Maglev test line to confirm the basic characteristics of the system. We analyzed the electric surge propagation characteristics of the coils used for the Miyazaki Maglev test line.

We call the propulsion coil at the side of vehicle "Front coil," and the other coil of the double-layered coils "Back coil." See Fig. 1. A sidewall levitation-guidance coil con- 


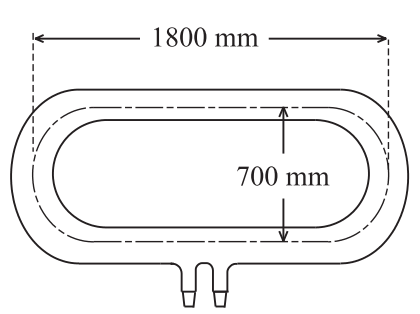

Front coil : 23 turns Back coil : 27 turns

Length between front coil center and back coil center : $1400 \mathrm{~mm}$

(a) Propulsion coil

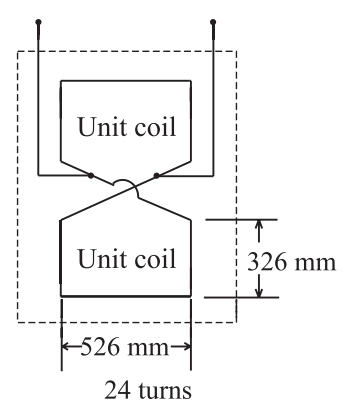

Length between upper coil center and lower coil center : $390 \mathrm{~mm}$ Coil pitch : $700 \mathrm{~mm}$

(b) Levitation-guidance coil
Fig. 2 Shape and size of coil

sists of upper and lower coils twisted like a figure "8."

We measured and simulated the surge propagation characteristics between two coils. The two coils combined in measurement and simulation were (1) front coil and front coil, (2) front coil and back coil and (3) front coil and levitation-guidance coil. Figure 2 shows the shape and size of the propulsion coil and levitation-guidance coil ${ }^{3)}$.

\subsection{Surge propagation characteristics between two propulsion coils}

To investigate the surge propagation characteristics between two double-layered propulsion coils, measurement and simulation results are discussed here.

\subsubsection{Measurement results}

We applied an impulse voltage to a coil and measured induced voltage on the other coil. As shown in Fig. 3, an impulse generator was connected to coil terminals and a wave digitizer recorded the applied and induced voltage waves. A semi-conductive layer was formed on the surface of the propulsion coil to prevent insulation deterio-

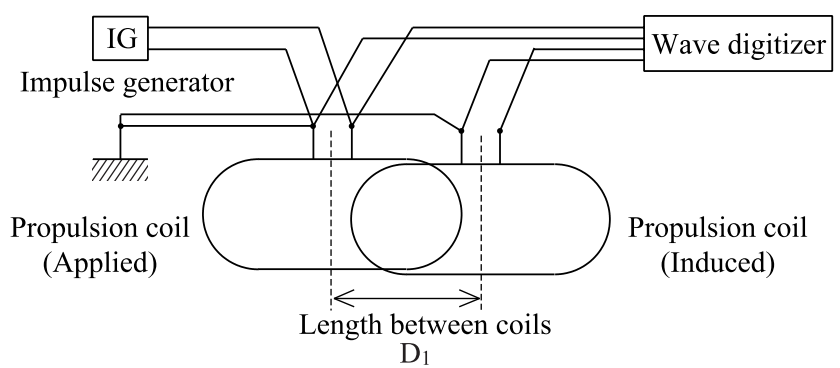

Fig. 3 Measurement circuit for surge propagation between two propulsion coils

Table 1 Conditions of measurement for surge propagation between two propulsion coils

\begin{tabular}{|c|c|c|c|}
\hline $\begin{array}{c}\text { Condition } \\
\text { No. }\end{array}$ & Combination of propulsion coils & $\mathrm{D}_{1}(\mathrm{~mm})$ & $\begin{array}{c}\text { Semi-conductive } \\
\text { layer }\end{array}$ \\
\hline 1 & Front coil + Front coil & 0 & Non-grounding \\
\hline 2 & Front coil + Front coil & 0 & Grounding \\
\hline 3 & Front coil + Front coil & 1,400 & Grounding \\
\hline 4 & Front coil + Back coil & 1,400 & Grounding \\
\hline
\end{tabular}

ration due to coronas ${ }^{2}$. One terminal of the conductor in each coil was grounded.

Table 1 shows the conditions of measurement. In the measurement of the surge propagation, we changed the length between coil centers $\left(D_{1}\right)$. We also measured the dependence on grounding semi-conductive layer.

\subsubsection{Simulation results}

We simulated the surge propagation characteristics between coils by using EMTP under the conditions described in Section 3.1.1.

Figure 4 shows the simulation model of the impulse generator used in measurement. After the capacitor $\left(\mathrm{C}_{1}\right)$ is charged, an impulse voltage is generated at the moment when the switch (SW) is closed.

Figure 5 shows the simulation model of double-layered propulsion coils. It is based on a transformer model in consideration of the surge propagation ${ }^{4)}$. The semiconductive layer formed on the coil surface is expressed as resistance in the model. The mutual coupling between coils is expressed as mutual inductance $(\mathrm{M})$.

The self-inductance $(\mathrm{L})$ was calculated from the phase difference between voltage and current when an alternating current flows in the coil. The distributed capacitance $(\mathrm{Cs})$ between coil and semi-conductive layer and the capacitance (Cc) between semi-conductive layers of each coil was measured by using an impedance meter. The resistance $\left(R_{s}\right)$ of semi-conductive layer was measured with a tester. At the moment when the circuit was cut off with the DC power source connected to coil terminals, an oscillating voltage appears between coil terminals. From the waveform of the oscillating voltage, the distributed capacitance $(\mathrm{C})$ in the coil was calculated by using the frequency of damped oscillation. The resistance $(R)$ of coil was also calculated by using an attenuation parameter with the self-inductance assumed as a known value ${ }^{5}$. The mutual inductance of coils that depends on the coil position was calculated from the voltage induced in a coil when an AC voltage was applied to the other coil. The

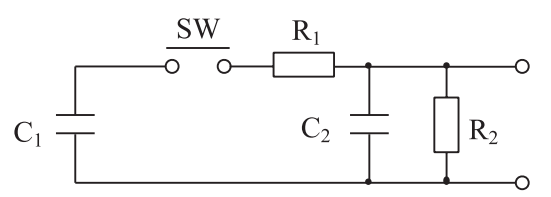

$$
\begin{aligned}
& \mathrm{C}_{1}: 0.1 \mu \mathrm{F} \\
& \mathrm{C}_{2}: 3 \mathrm{nF} \\
& \mathrm{R}_{1}: 100 \Omega \\
& \mathrm{R}_{2}: 2 \mathrm{k} \Omega
\end{aligned}
$$

Fig. 4 Simulation model for impulse generator

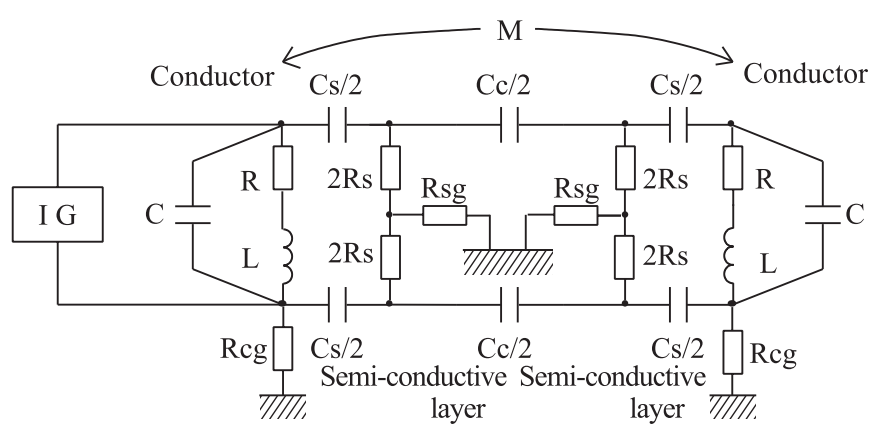

Fig. 5 Simulation model for surge propagation between two propulsion coils 

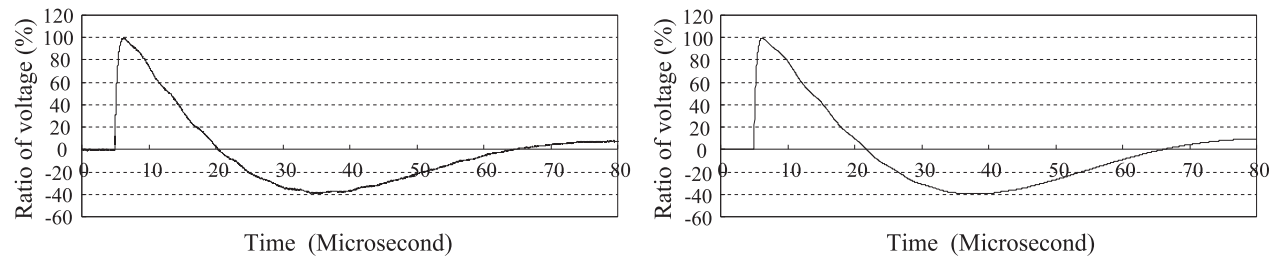

Applied voltage
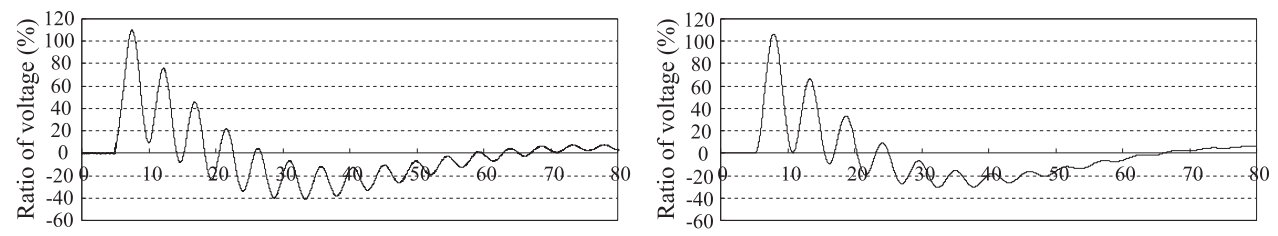

Time (Microsecond)

Waves under condition 1
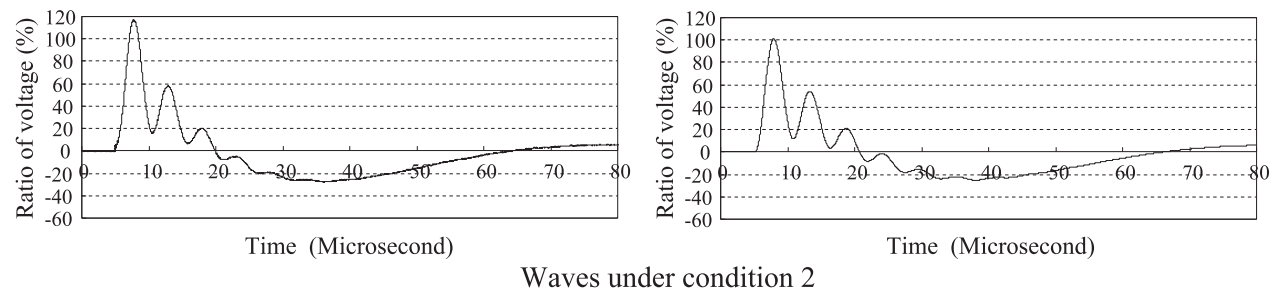

Waves under condition 2
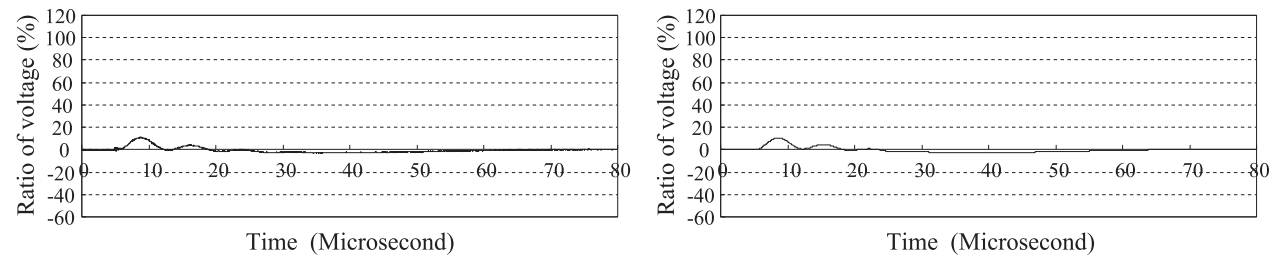

Waves under condition 3
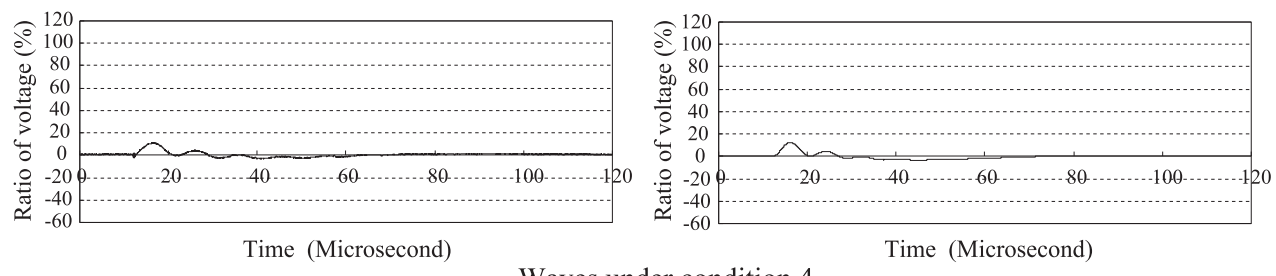

Waves under condition 4

(Left: Measurement, Right: Simulation)

Fig. 6 Measured and simulated results of surge propagation between two propulsion coils

grounding resistance ( $\mathrm{Rsg}$ ) of semi-conductive layer and that (Rcg) of coil terminal were $1 \mathrm{Ohm}$, which was the grounding resistance of our test building.

The surge propagation at different values of $M$ and Cc was simulated under the conditions of the measurement shown in Table 1. Table 2 shows the circuit parameters used for the simulation.

\subsubsection{Comparison between measured and simulated re- sults}

Figure 6 shows the measured results on the left side and the simulated results on the right side. Table 3 shows the oscillation frequency and the peak value of the induced voltage as the percentage to the peak value of applied voltage.

The results under the conditions 1 and 2 were com- pared to estimate the effect of grounding the semi-conductive layer. The peak value of induced voltage was 10 to $20 \%$ larger than the applied voltage under both conditions. On the other hand, when the semi-conductive layer was grounded, the oscillation frequency became smaller (from $210 \mathrm{kHz}$ to $193 \mathrm{kHz}$ ), and the induced voltage wave converged faster, presumably because the resistance of semi-conductive layer consumed the electro-magnetic energy induced in the coil since the semi-conductive layer was grounded.

To investigate the dependence on the length between coil centers, the results under the conditions 2 and 3 were compared. The peak value of induced voltage was about $20 \%$ larger than the applied voltage under the condition 2. However, the weaker the electro-magnetic coupling was, the smaller the peak value of induced voltage became. 
Table 2 Parameters used for simulation

\begin{tabular}{|c|c|c|c|c|c|}
\hline & $\mathrm{L}(\mathrm{mH})$ & $\mathrm{R}(\mathrm{Ohm})$ & $\mathrm{C}(\mathrm{nF})$ & Rs (k Ohm) & $\mathrm{Cs}(\mathrm{nF})$ \\
\hline Front coil & 1.55 & 62 & 0.74 & 3 & 2.3 \\
\hline Back coil & 2.04 & 79 & 0.78 & 3 & 2.5 \\
\hline $\begin{array}{l}\text { Condition } \\
\text { No. }\end{array}$ & \multicolumn{3}{|c|}{$\begin{array}{c}\text { Combination of propulsion } \\
\text { coils }\end{array}$} & $\mathrm{M}(\mathrm{mH})$ & $\mathrm{Cc}(\mathrm{nF})$ \\
\hline 1,2 & \multicolumn{3}{|c|}{ Front coil + Front coil } & 0.92 & 0.85 \\
\hline 3 & \multicolumn{3}{|c|}{ Front coil + Front coil } & 0.10 & 0.25 \\
\hline 4 & \multicolumn{3}{|c|}{ Front coil + Back coil } & 0.12 & 0.25 \\
\hline
\end{tabular}

Table 3 Comparison between measured and simulated results

\begin{tabular}{|c|c|c|c|c|}
\hline \multirow{2}{*}{$\begin{array}{c}\text { Condition } \\
\text { No. }\end{array}$} & \multicolumn{2}{|c|}{ Oscillation frequency of induced voltage } & \multicolumn{2}{c|}{ Peak value of induced voltage } \\
\cline { 2 - 5 } & Measurement & Simulation & Measurement & Simulation \\
\hline 1 & $210 \mathrm{kHz}$ & $187 \mathrm{kHz}$ & $110 \%$ & $106 \%$ \\
\hline 2 & $193 \mathrm{kHz}$ & $182 \mathrm{kHz}$ & $117 \%$ & $101 \%$ \\
\hline 3 & $136 \mathrm{kHz}$ & $146 \mathrm{kHz}$ & $11 \%$ & $11 \%$ \\
\hline 4 & $110 \mathrm{kHz}$ & $125 \mathrm{kHz}$ & $11 \%$ & $12 \%$ \\
\hline
\end{tabular}

When coils were attached under the condition 3 where the length between coil centers was $1,400 \mathrm{~mm}$, the peak value of induced voltage became $10 \%$ of the applied voltage. The oscillation frequency of induced voltage was $193 \mathrm{kHz}$ under the condition 2 and $136 \mathrm{kHz}$ under the condition 3 .

Next, we compared the results under the conditions 3 (front coil + front coil) and 4 (front coil + back coil) to investigate the dependence on the propulsion coil combination when coils were attached at the actual positions. Although the peak values of induced voltage under the conditions 3 and 4 were almost the same, the oscillation frequency of induced voltage under the condition 4 was smaller than that under the condition 3 . This result could be easily understood since the self-inductance and mutual inductance of back coil were larger than those of front coil.

We then compared the measured and simulated results. Although the simulated ratio of the peak value of the induced voltage to the applied voltage was slightly smaller than the measured ratio under the conditions 1 and 2 , they were generally in agreement with each other in waveform, oscillation frequency and other factors.

\subsection{Surge propagation characteristics between the propulsion coil and the levitation-guidance coil}

This section focuses on the surge propagation characteristics between the propulsion coil and the levitationguidance coil from the viewpoint of measurement and simulation.

\subsubsection{Measurement results}

We attached coils as shown in Fig. 7 to measure the surge propagation. An impulse generator (IG) was connected to propulsion coil terminals and the induced voltage of levitation-guidance coil was recorded under the conditions 5, 7 and 9 of Table 4 . Contrary to this, an impulse generator was connected to the levitation-guidance coil and the induced voltage of propulsion coil was recorded under the conditions 6 and 8 . The length between coil centers $\left(D_{1}\right)$ was changed as shown in Table 4 in the measurement of surge propagation.

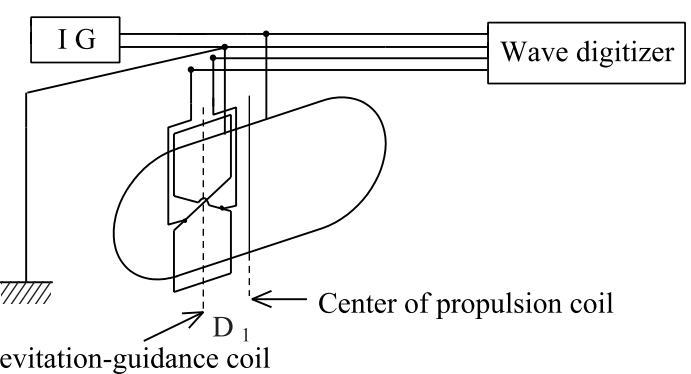

Center of levitation-guidance coil

Fig. 7 Measurement circuit for surge propagation between the propulsion coil and the levitation-guidance coil

Table 4 Conditions of measurement for surge propagation between the propulsion coil and the levitationguidance coil

\begin{tabular}{|c|c|c|c|c|}
\hline $\begin{array}{c}\text { Condition } \\
\text { No. }\end{array}$ & Applied coil & Induced coil & $\begin{array}{c}\mathrm{D}_{1} \\
(\mathrm{~mm})\end{array}$ & $\begin{array}{c}\text { Semi-conductive } \\
\text { layer }\end{array}$ \\
\hline 5 & Front coil & $\begin{array}{c}\text { Levitation-guidance } \\
\text { coil }\end{array}$ & 350 & Non-grounding \\
\hline 6 & $\begin{array}{c}\text { Levitation-guidance } \\
\text { coil }\end{array}$ & Front coil & 350 & Non-grounding \\
\hline 7 & Front coil & $\begin{array}{c}\text { Levitation-guidance } \\
\text { coil }\end{array}$ & 350 & Grounding \\
\hline 8 & $\begin{array}{c}\text { Levitation-guidance } \\
\text { coil }\end{array}$ & Front coil & 350 & Grounding \\
\hline 9 & Front coil & $\begin{array}{c}\text { Levitation-guidance } \\
\text { coil }\end{array}$ & 1050 & Grounding \\
\hline
\end{tabular}

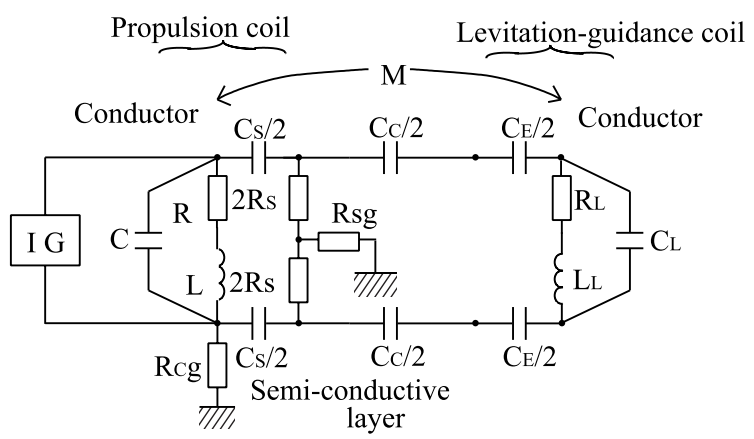

Fig. 8 Simulation model for surge propagation between the propulsion coil and the levitation-guidance coil

Table 5 Simulation model for surge propagation between two propulsion coils

\begin{tabular}{|c|c|c|c|c|}
\hline & $\begin{array}{c}\mathrm{L}_{\mathrm{L}} \\
(\mathrm{mH})\end{array}$ & $\begin{array}{c}\mathrm{R}_{\mathrm{L}} \\
(\mathrm{Ohm})\end{array}$ & $\begin{array}{c}\mathrm{C}_{\mathrm{L}} \\
(\mathrm{nF})\end{array}$ & $\begin{array}{c}\mathrm{C}_{\mathrm{E}} \\
(\mathrm{k} \text { Ohm })\end{array}$ \\
\hline $\begin{array}{c}\text { Levitation-guidance } \\
\text { coil }\end{array}$ & 0.246 & 9.2 & 3.2 & 0.8 \\
\hline Condition No. & \multicolumn{2}{|c|}{$\mathrm{M}(\mathrm{mH})$} & \multicolumn{2}{|c|}{$\mathrm{Cc}(\mathrm{nF})$} \\
\hline $5-8$ & \multicolumn{2}{|c|}{0.173} & \multicolumn{2}{|c|}{0.25} \\
\hline 9 & \multicolumn{2}{|c|}{-0.019} & \multicolumn{2}{|c|}{0.12} \\
\hline
\end{tabular}

\subsubsection{Simulation results}

We simulated the surge propagation characteristics between the propulsion coil and the levitation-guidance coil. The simulation model of the impulse generator was the same as that described in Section 3.1.2. Figure 8 shows the simulation model for the setup shown in Fig. 7. The circuit parameters were measured by the method described in Section 3.1.2 and the results are shown in Table 5. CE in Fig. 8 is the capacitance of insulator of the levitation-guidance coil. 

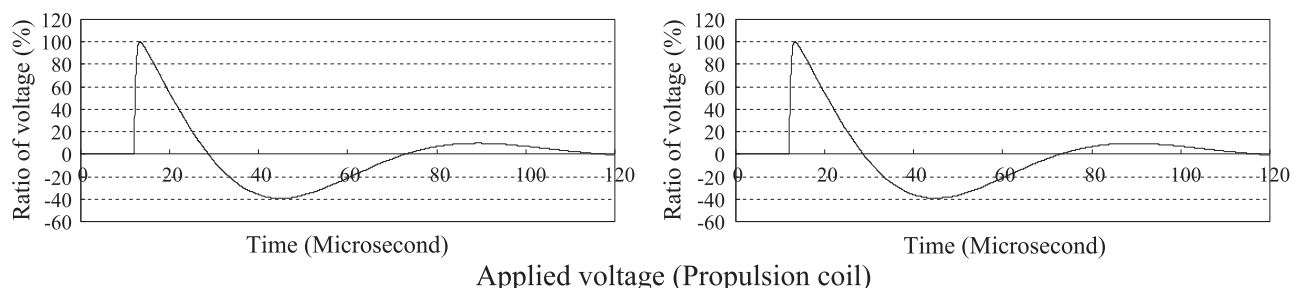

Applied voltage (Propulsion coil)
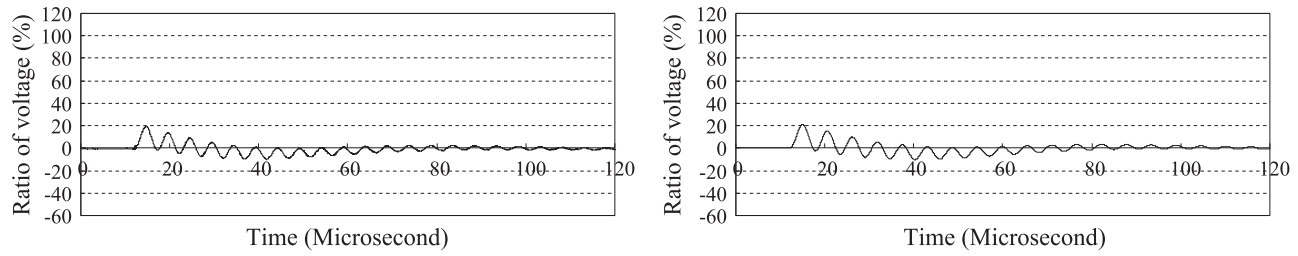

Waves under condition 5
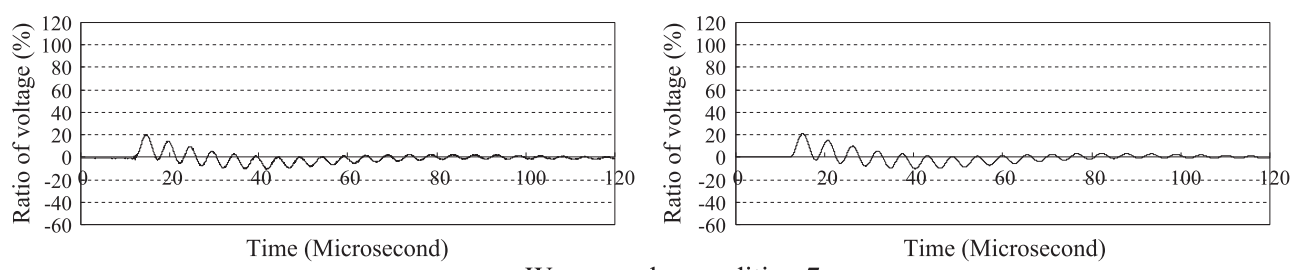

Waves under condition 7
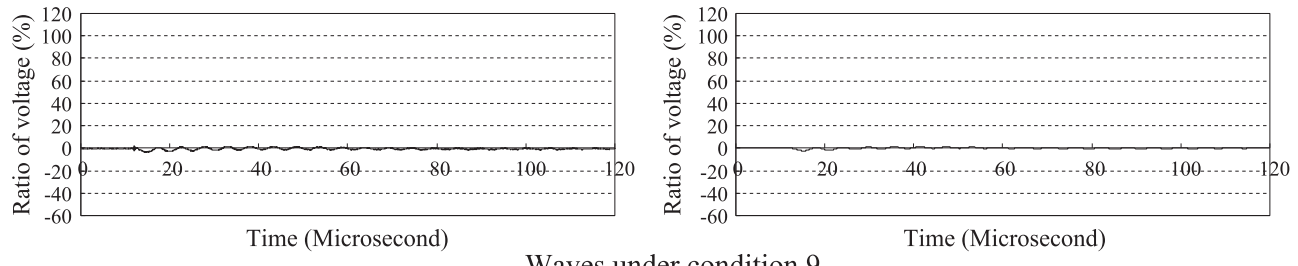

Waves under condition 9
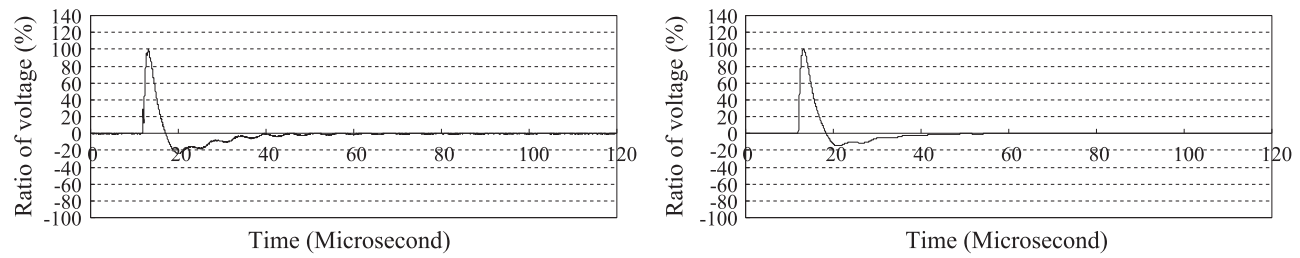

Applied voltage (Levitation-guidance coil)
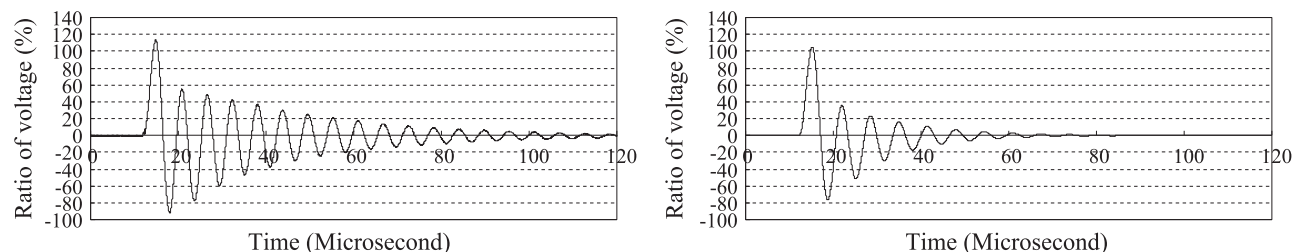

Waves under condition 6
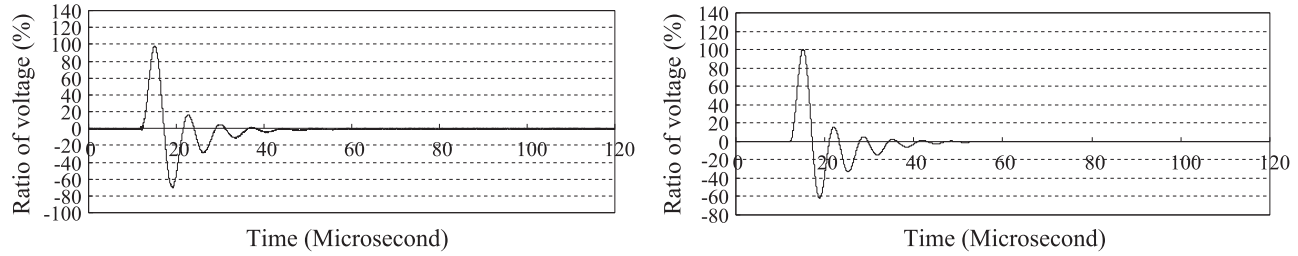

Waves under condition 8

(Left: Measurement, Right: Simulation)

Fig. 9 Measured and simulated results of surge propagation between the propulsion coil and the levitation-guidance coil 
3.2.3 Comparison between measured and simulated results

Figure 9 shows the measured results on the left side and the simulated results on the right side. The results under the conditions 5 and 7 were compared to investigate the effect of grounding the semi-conductive layer, when an impulse voltage was applied to the propulsion coil. The oscillation frequencies and peak values of induced voltage were nearly equal. Therefore, grounding the semi-conductive layer did not have much influence on the induced voltage. The results under the conditions 7 and 9 were also compared to investigate the influence of electro-magnetic coupling. The results clarified that the weaker the electro-magnetic coupling was, the smaller the peak value of induced voltage became, and that the polarity was reversed when the mutual inductance (M) became negative.

Next, the results under the conditions 6 and 8 were compared to investigate the effect of grounding the semiconductive layer, when an impulse voltage was applied to the levitation-guidance coil. When the semi-conductive layer was grounded, the oscillation frequency became smaller (from $170 \mathrm{kHz}$ to $130 \mathrm{kHz}$ ), and the induced voltage wave converged faster.

Finally, we compared the measured and simulated results to find that they were generally in agreement with each other in waveform, oscillation frequency and other factors except for the result under the condition 6 for unknown reasons.

\subsection{Surge propagation characteristics between propulsion coils through levitation-guidance coils}

As described in Chapter 2, levitation-guidance coils on both sidewalls are connected with a null flux cable. This makes the propulsion coils on both sidewalls electromagnetically coupled. This section focuses on the surge propagation characteristics between propulsion coils through levitation-guidance coils.

\subsubsection{Measurement results}

We measured the surge propagation of coils as shown in Fig. 10. An impulse generator was connected to pro- pulsion coil terminals to record the applied and induced voltage waves.

\subsubsection{Simulation results}

We simulated the surge propagation characteristics between propulsion coils through levitation-guidance coils. Figure 11 shows the simulation model for the setup shown in Fig. 10. This model is based on the model for simulation of the surge propagation between the propulsion coil and the levitation-guidance coil. The circuit parameters are shown in Tables 2 and 5 .

\subsubsection{Comparison between measured and simulated re- sults}

Figure 12 shows the measured results on the left side and the simulated results on the right side. The lower waves in Fig. 12 were the results under the condition that the semi-conductive layer was grounded and the upper waves in Fig. 12 were under the condition that the semiconductive layer was not grounded. The peak value of the induced voltage was about $10 \%$ smaller than the applied voltage under both conditions. When the semi-conductive layer was grounded, the induced voltage wave converged faster.

The frequency analysis of measured waves showed that the frequency of the wave was $225 \mathrm{kHz}$ and $170 \mathrm{kHz}$ when the semi-conductive layer was grounded and 216 $\mathrm{kHz}$ and $135 \mathrm{kHz}$ when the semi-conductive layer was not grounded. In Fig. 12, therefore, the frequency of the upper

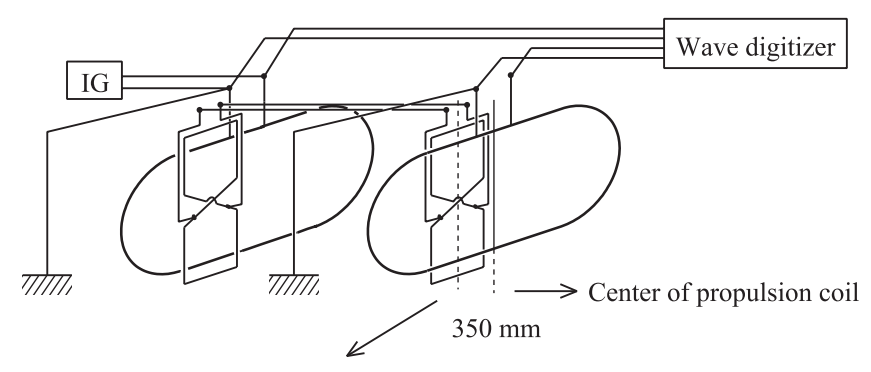

Center of levitation-guidance coil

Fig. 10 Measurement circuit for surge propagation between propulsion coils through levitationguidance coils

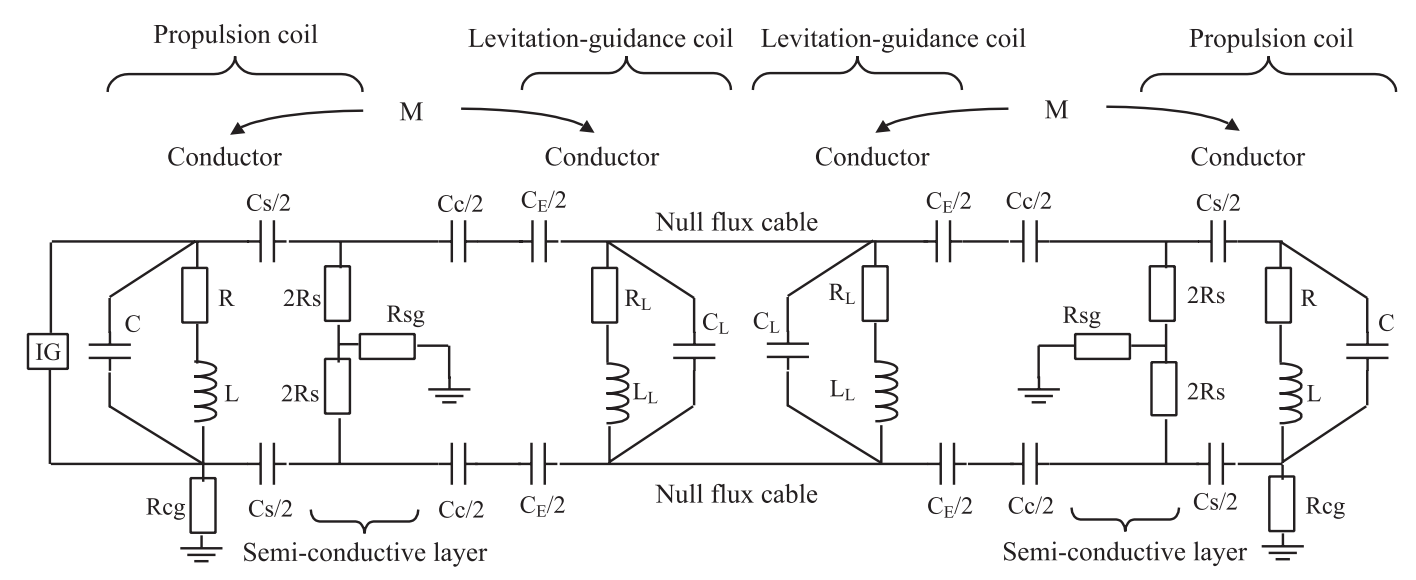

Fig. 11 Simulation model for surge propagation between propulsion coils through levitation-guidance coil 

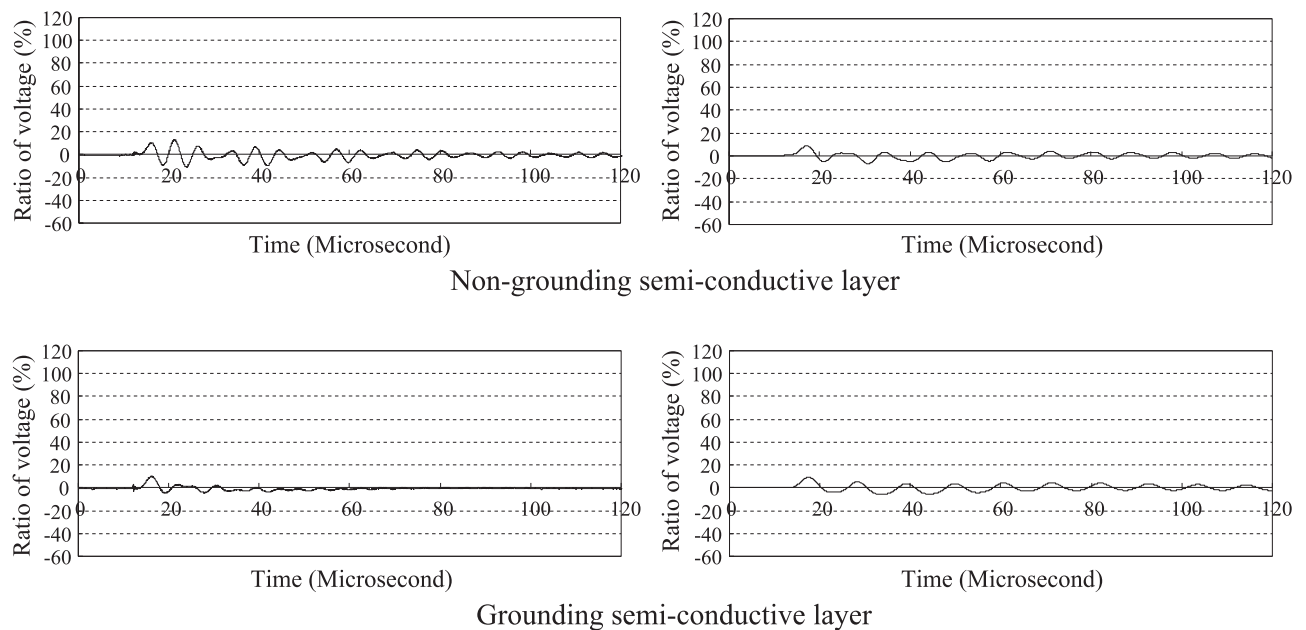

(amulation)

Fig. 12 Measured and simulated results of surge propagation between propulsion coils through levitation-guidance coils

wave consisted of the frequency under the conditions 5 (wave $200 \mathrm{kHz}$ ) and 6 (wave $175 \mathrm{kHz}$ ), and the frequency of the lower wave consisted of the frequency under the conditions 7 (wave $201 \mathrm{kHz}$ ) and 8 (wave $135 \mathrm{kHz}$ ) as shown in Section 3.2.3.

The measured and simulated results were generally in agreement with each other in waveform, but the oscillation frequency by simulation was slightly lower than the measured value.

\section{Conclusions}

We measured the surge propagation characteristics between coils and simulated with proposed simulation models. It was shown that the values simulated by EMTP which used our simulation models agreed well with the measured values. Therefore, it was verified that the proposed surge propagation models for simulation were very useful to estimate the surge propagation of coils used for Maglev.

This research has been assisted by a government subsidy.

\section{References}

1) Sawada, K et al.: "Development of Ground coil for Yamanashi Test Line (in Japanese)," Jointed Railway Technology Symposium (J-Rail 1995), No. 95, pp. 337338, 1995.

2) Nakashima, H: "Superconducting Magnets for Magnetically Levitating Vehicles (in Japanese)," National Convention of IEEJ, Symposium, S. 20-3, pp. S. 20-9S. 20-12, 1996.

3) Murai, T: "Characteristics of Superconducting Maglev System Combining Propulsion, Levitation, Guidance and Generator (in Japanese)," RTRI REPORT, Special No. 12, 1997.

4) Ueda, T et al.: "Measurement of Transformer Transfer Voltage and a Study of its Modeling (in Japanese)," Trans. of IEEJ, Vol. 115-B, No. 12, pp. 1494-1500, 1995.

5) Ema, S: "Surge Analysis of the MAGLEV Coil for Propulsion and Guidance (in Japanese)," Trans. of IEEJ, Vol. 115-D, No. 12, pp. 1537-1544, 1995. 